\title{
MENINGKATKAN PELAYANAN DAN AKUNTABILITAS MELALUI PENGEMBANGAN SISTEM INFORMASI PADA ADMINISTRASI SERVICE KENDARAAN BERMOTOR
}

\author{
Nofiyani \\ Program Studi Sistem Informasi, Universitas Budi Luhur \\ Jalan Ciledug Raya, Petukangan Utara, Jakarta Selatan \\ nofiyani@budiluhur.ac.id
}

\begin{abstract}
The more the tightness of business competition requires every company to increase competitiveness continuously. Increased service and accountability in presenting data, both to customers and business owners/companies are expected to increase the competitiveness and resilience of the company. Will remain strong in every condition. Therefore, for the customer relationship with the company and the business owner to run the business well, the service will be improved by developing an information system. The model used in developing information systems is Rapid Application Development (RAD). The RAD method is an information system development with a relatively short time so the system development costs are lower. The steps in this research are data collection, system requirements planning, system planning, and implementation. Based on the Black-Box test results, the system developed has been following its function and the task of the user of the system is more easily and quickly completed, and the presentation of information and reports that will be given more quickly and accurately. Four reports will be made as accountability for work reports, reports work order requests, parts request reports, warranty claims, and after-sales service reports.
\end{abstract}

Keywords - Service, Accountability, Development of Information System, Rapid Application Development (RAD)

\begin{abstract}
Semakin ketatnya persaingan bisnis, menuntut setiap perusahaan untuk meningkatkan daya saingnya secara terus menerus. Meningkatan pelayanan dan akuntabilitas dalam penyajian data, baik kepada pelanggan maupun pemilik usaha / perusahaan diharapkan dapat meningkatkan daya saing dan ketahanan perusahaan. Sehingga bisnis akan tetap kuat dalam menghadapi setiap kondisi. Karenanya agar hubungan pelanggan dengan perusahaan dan pemilik usaha dengan pelaksana usaha berjalan dengan baik, maka dilakukan peningkatan pelayanan dengan mengembangkan sistem informasi. Model yang digunakan dalam pengembangan sistem informasi adalah Rapid Application Development (RAD). Metode RAD merupakan pengembangan sistem informasi dengan waktu yang relatif singkat sehingga biaya pengembangan sistem menjadi lebih rendah. Tahapan yang dilakukan dalam penelitian ini adalah mengumpulkan data, merencanakan kebutuhan sistem (Requirement Planning), desain sistem (Design System) dan melakukan implementasi (Implementation). Berdasarkan hasil pengujian Black-Box Testing, sistem yang dikembangkan sudah sesuai dengan fungsinya sehingga tugas dan pekerjaan dari pengguna sistem lebih mudah dan cepat selesai, serta penyajian informasi dan laporan yang akan diberikan lebih cepat dan akurat.Terdapat empat laporan yang akan dibuat sebagai pertanggung jawaban kasir ke workshop manajer, diantaranya laporan work order, laporan permintaan suku cadang, laporan warranty claim dan after sales service report.
\end{abstract}

Katakunci - Pelayanan, Akuntabilitas, Pengembangan Sistem Informasi, Rapid Application Development (RAD).

\section{PENDAHULUAN}

Semakin pesatnya pertumbuhan dan perubahan ekonomi serta persaingan bisnis yang semakin ketat, menimbulkan banyak konsekuensi dalam persaingan perusahaan. Perusahaan dituntut untuk meningkatkan daya saingnya secara terus menerus [7].

Dengan meningkatan pelayanan dan akuntabilitas dalam penyajian data baik kepada pelanggan maupun pemilik usaha / perusahaan diharapkan dapat meningkatkan daya saing dan ketahanan perusahaan. Sehingga bisnis akan tetap kuat dalam menghadapi setiap kondisi. Dalam akuntabilitas terkandung kewajiban untuk menyajikan dan melaporkan segala kegiatan kepada pihak yang lebih tinggi. Media pertanggungjawaban akuntabilitas tidak terbatas pada laporan pertanggungjawaban, akan tetapi juga mencakup aspek-aspek kemudahan mendapatkan informai, sehingga akuntabilitas dapat tumbuh pada lingkungan yang mengutamakan keterbukaan sebagai landasan pertanggungjawaban [3]. Sehingga penyalahgunaan tanggung jawab dapat terhindarkan.

Karenanya berbagai upaya dilakukan agar hubungan pelanggan dengan perusahaan dan pemilik 
usaha dengan pelaksana usaha berjalan dengan baik [4] Salah satunya dengan meningkatkan pelayanan dengan mengembangkan sistem informasi. Dengan menggunakan sistem komputer dan perangkat teknologi lainnya informasi dapat dikelola dan disampaikan kepada yang membutuhkan secara cepat dan akurat, serta memudahkan pegawai dalam menyelesaikan tugas dan pekerjaan masing-masing terutama berhubungan dengan pelayanan pada pelanggan [9].

Untuk dapat menghasilkan informasi yang berkualitas dan baik diperlukan tahapan dalam pengembangan sistem informasi. Rapid Application Development (RAD) merupakan salah satu model yang dapat digunakan untuk pengembangan sistem informasi. Metode RAD merupakan pengembangan sistem informasi dengan waktu yang relatif singkat. Untuk pengembangan sistem informasi yang normal membutuhkan waktu minimal 180 hari. Namun dengan metode RAD suatu sistem dapat diselesaikan hanya dalam waktu 60-90 hari sehingga biaya pengembangan sistem menjadi lebih rendah [1].

Penelitian yang dilakukan oleh Jijon Raphita Sagala yang menerapkan Model Rapid Application Development (RAD) dalam pengembangan sistem informasi penjadwalan belajar mengajar agar akifitas penjadwalan dapat dilaksanakan dengan baik [6]. Sedangkan penelitian yang dilakukan oleh Tenia Wahyuningrum dan Dwi Januarita menerapkan Metode Rapid Application Development (RAD) dalam Perancangan WEB e-Commerce untuk Produk Unggulan Desa [8]. Berdasarkan penelitian tersebut model RAD merupakan model pengembangan sistem informasi yang efisien dari segi waktu karena hanya membutuhkan waktu kurang lebih 60 hari.

\section{METODE PENELITIAN}

Metode penelitian yang digunakan adalah metode penelitian kualitatif, dimana data diperoleh melalui:

1. Wawancara dengan pihak yang berwenang untuk memperoleh data yang lebih lengkap.

2. Melakukan observasi untuk mengamati secara langsung prosedur sistem berjalan.

3. Menganalisa dokumentasi yang tersedia atau yang sudah dikumpulkan.

Metode pengembangan sistem yang digunakan adalah Rapid Application Development (RAD) yang merupakan model pengembangan perangkat lunak yang termasuk dalam teknik inkremental (bertingkat). Rapid Application Development (RAD) menekankan pada pengembangan perangkat lunak yang pendek, singkat, dan cepat [6]. Model Rapid Application Development (RAD) mempunyai tiga tahapan:

1. Rencana Kebutuhan (Requirement Planning) Pada tahap ini, pengguna dan analis akan bertemu untuk mengidentifikasi tujuan sistem dan juga mengidentifikasi syarat-syarat informasi yang muncul dari tujuan tersebut. Orientasi dalam tahap ini adalah menyelesaikan masalah-masalah pengguna [5].

2. Desain Sistem (Design System)

Tahap ini adalah tahap merancang dan memperbaiki. Analis dan programmer dapat bekerja membangun dan menunjukkan representasi visual desain dan pola kerja kepada pengguna [1]. Pengguna merespon prototype yang ada dan analis akan memperbaiki rancangan berdasarkan masukan dan respon dari pengguna. Pola kerja ini akan mendorong pengembangan hingga tingkat akhir [5]. Keaktifan pengguna yang terlibat menentukan pencapaian tujuan karena akan dilakukan proses desain dan perbaikan-perbaikan apabila masih terdapat ketidaksesuaian desain antara pengguna dan analis[8].

3. Implementasi (Implementation)

Analis dan pengguna bekerja secara intens selama tahap perancangan [5]. Pada tahap ini programmer akan mengembangkan desain program yang telah disetujui oleh penguna dan analis. Sebelum diaplikasikan pada suatu organisasi, program terlebih dahulu dilakukan ujicoba apakah masih terdapat kesalahan atau tidak [1].

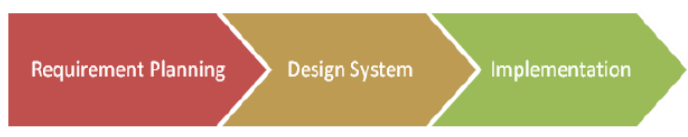

Gambar 1. Tahapan Metode RAD [8]

\section{HASIL DAN PEMBAHASAN}

A. Tahap Rencana Kebutuhan (Requirement Planning)

1. Uraian Prosedur atau Prosedur Kerja Sistem usulan :

a. Pendataan Pelanggan

Setiap ada pelanggan baru yang datang, Front Desk akan melakukan pendataan pelanggan berdasarkan STNK yang diberikan. Dengan mencatat data pelanggan dan data sepeda motor pelanggan dalam history card. Setelah dilakukan pendataan, pelanggan akan mendapatkan kartu pelanggan. Sehingga, bila sewaktu-waktu pelanggan akan melakukan service hanya dengan menunjukkan kartu pelanggan saja.

b. Penerimaan Order

Pelanggan memberikan kartu pelanggan dan menyampaikan order kerja atau keluhan - keluhan yang dialami sepeda motornya, kemudian Front desk yang dibantu oleh Technical Inspector akan 
membuatkan work order yang akan diserahkan ke mekanik agar mekanik dapat mengerjakannya. Apabila terdapat kerusakan parts, mekanik akan membuat permintaan suku cadang yang langsung dicatat dalam work order setelah melakukan konfirmasi pada pelanggan yang bersangkutan. Kemudian wo permintaan suku cadang tersebut disampaikan ke bagian pengawas suku cadang. Penanganan pekerjaan ulang dilakukan oleh mekanik.

\section{c. Pembayaran}

Pelanggan akan melakukan pembayaran apabila sepeda motornya sudah selesai diservice. Pembayaran dapat berupa uang tunai dan Kartu Perawatan Berkala. Untuk pembayaran berupa uang tunai, pelanggan akan mendapatkan kwitansi sebagai bukti pembayaran. Sedangkan untuk pembayaran melalui KPB I (km 500 atau bulan 2),II ( $\mathrm{km} 2000$ atau bulan 4),III ( $\mathrm{km} 4000$ atau bulan 6) dan IV (km 6000 atau bulan 8) dapat dilakukan apabila sepeda motor tersebut dalam perawatan berkala dan tidak melewati bulan dan kilometer motor yang sudah ditentukan. Dengan mencatat data sepeda motor dan tanggal pemeriksaan dalam KPB pada saat proses pembayaran, kemudian KPB tersebut disimpan untuk ditagih setiap pertengahan bulan dan akhir bulan pada pihak PT. AHM.

\section{d. Pengajuan Claim}

PT. AHM (Astra Honda Motor) memberikan kebijaksanaan terhadap AHASS yang ditunjuk untuk menangani claim kepada setiap pelanggan yang baru membeli sepeda motor Honda. Pelanggan berhak melakukan pengajuan claim apabila sepeda motor yang di claim tersebut telah di cek dan ternyata terdapat kesalahan dari pihak produsen (pabrik), maka data - data pengajuan claim dicatat dalam formulir pengajuan warranty claim yang disertai pencatatan no buku service yang ada dikartu KPB dan membuat formulir pengajuan warranty claim untuk di claim ke pihak PT. AHM.

\section{e. Buat Laporan}

Laporan akan dibuat setiap akhir bulan untuk pertanggung jawaban ke workshop manajer, laporan work order untuk mengetahui rincian order kerja yang sudah dikerjakan dan laporan permintaan suku cadang untuk mengetahui rincian permintaan suku cadang, sedangkan after sales service report dan formulir tagihan KPB akan dibuat setiap pertengahan bulan dan akhir bulan untuk penagihan ke pihak PT. AHM.

\section{Kebutuhan Informasi Sistem}

Tabel 1. Kebutuhan Informasi Sistem

\begin{tabular}{|c|c|c|c|}
\hline No. & Informasi & Tujuan & Frekuensi \\
\hline 1. & $\begin{array}{l}\text { Kartu Pelanggan Sebagai } \\
\text { bukti berlangganan dan } \\
\text { alat untuk melakukan } \\
\text { order kerja }\end{array}$ & $\begin{array}{l}\text { Pelang } \\
\text { gan }\end{array}$ & $\begin{array}{l}\text { Setiap } \\
\text { ada } \\
\text { pelangg } \\
\text { an baru } \\
\text { atau } \\
\text { pelangg } \\
\text { an yang } \\
\text { kehilan } \\
\text { gan } \\
\text { kartu } \\
\text { pelangg } \\
\text { annya }\end{array}$ \\
\hline 2. & $\begin{array}{lr}\text { Formulir } & \text { Pengajuan } \\
\text { Warranty Claim Untuk } & \text { Claim } \\
\text { mengajukan } & \text { claim dari } \\
\text { pelanggan } & \text { yang } \\
\text { memenuhi } & \text { ketentuan } \\
\text { garansi / jaminan } \\
\text { penggantian parts akibat } \\
\text { kesalahan teknis / } \\
\text { kesalahan } \\
\text { pabrik }\end{array}$ & $\begin{array}{l}\text { PT. } \\
\text { Astra } \\
\text { Honda } \\
\text { Motor }\end{array}$ & $\begin{array}{l}\text { Setiap } \\
\text { kendara } \\
\text { an yang } \\
\text { memen } \\
\text { uhi } \\
\text { persyara } \\
\text { tan } \\
\text { claim. }\end{array}$ \\
\hline 3. & $\begin{array}{l}\text { Bukti Pembayaran } \\
\text { Sebagai bukti } \\
\text { pembayaran atas jasa } \\
\text { service dan penggantian } \\
\text { spare part / suku cadang, } \\
\text { oli dan lain-lain sesuai } \\
\text { dengan work order }\end{array}$ & $\begin{array}{l}\text { Pelang } \\
\text { gan } \\
\text { dan } \\
\text { Techni } \\
\text { cal } \\
\text { Inspect } \\
\text { or }\end{array}$ & $\begin{array}{l}\text { Setiap } \\
\text { terjadi } \\
\text { transaks } \\
\mathrm{i} \\
\text { pembay } \\
\text { aran }\end{array}$ \\
\hline 2. & 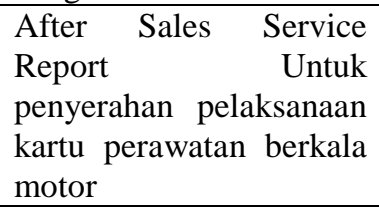 & $\begin{array}{l}\text { PT. } \\
\text { Astra } \\
\text { Honda } \\
\text { Motor }\end{array}$ & $\begin{array}{l}\text { Setiap } \\
\text { akhir } \\
\text { bulan }\end{array}$ \\
\hline 5. & $\begin{array}{lr}\text { Formulir } & \text { Tagihan KPB } \\
\text { Untuk } & \text { melakukan } \\
\text { penagihan } & \text { biaya } \\
\text { pelaksanaan } & \text { perawatan } \\
\text { berkala } & \\
\end{array}$ & $\begin{array}{l}\text { PT. } \\
\text { Astra } \\
\text { Honda } \\
\text { Motor }\end{array}$ & $\begin{array}{l}\text { Setiap } \\
\text { akhir } \\
\text { bulan }\end{array}$ \\
\hline 6. & $\begin{array}{l}\text { Laporan Work Order } \\
\text { untuk mengetahui rincian } \\
\text { order kerja yang sudah } \\
\text { dikerjakan }\end{array}$ & $\begin{array}{l}\text { Works } \\
\text { hop } \\
\text { Manag } \\
\text { er }\end{array}$ & $\begin{array}{l}\text { Setiap } \\
\text { akhir } \\
\text { bulan }\end{array}$ \\
\hline 7. & $\begin{array}{l}\text { Laporan Permintaan } \\
\text { Suku Cadang untuk } \\
\text { mengetahui rincian } \\
\text { permintaan suku cadang }\end{array}$ & $\begin{array}{l}\text { Works } \\
\text { hop } \\
\text { Manag } \\
\text { er }\end{array}$ & $\begin{array}{l}\text { Setiap } \\
\text { akhir } \\
\text { bulan }\end{array}$ \\
\hline 8. & $\begin{array}{lr}\text { Laporan Warranty Claim } \\
\text { untuk } & \text { mengetahui } \\
\text { pengajuan } & \text { warranty } \\
\text { claim } & \end{array}$ & $\begin{array}{l}\text { Works } \\
\text { hop } \\
\text { Manag } \\
\text { er }\end{array}$ & $\begin{array}{l}\text { Setiap } \\
\text { akhir } \\
\text { bulan }\end{array}$ \\
\hline
\end{tabular}


3. Use Case Diagram

a. File Master

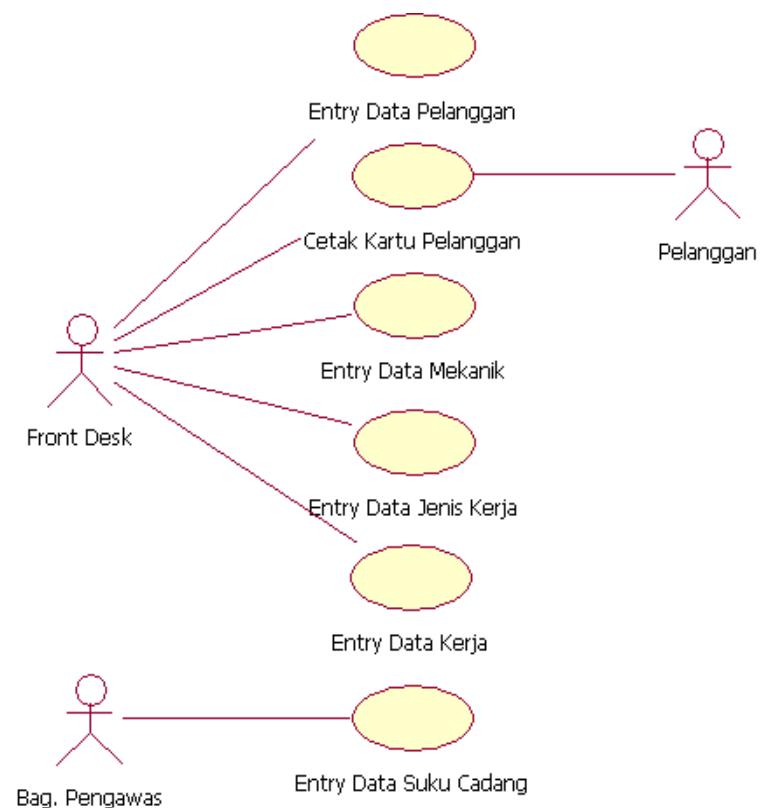

Gambar 2. Use Case Diagram File Master

b. Penerimaan Order
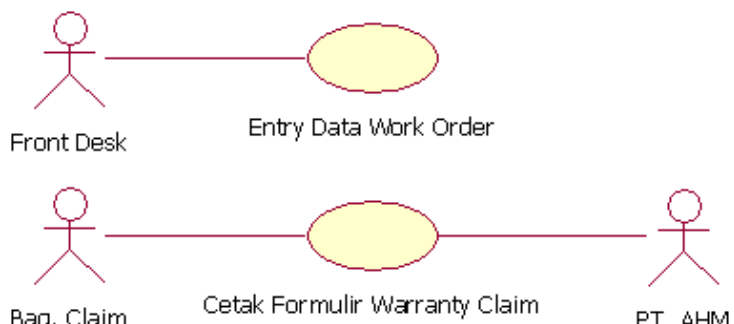

Gambar 3. Use Case Diagram Penerimaan Order

c. Transaksi Pembayaran

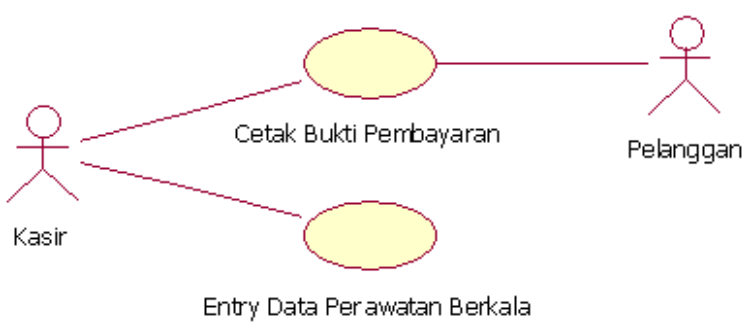

Gambar 4. Use Case Diagram Transaksi Pembayaran d. Laporan

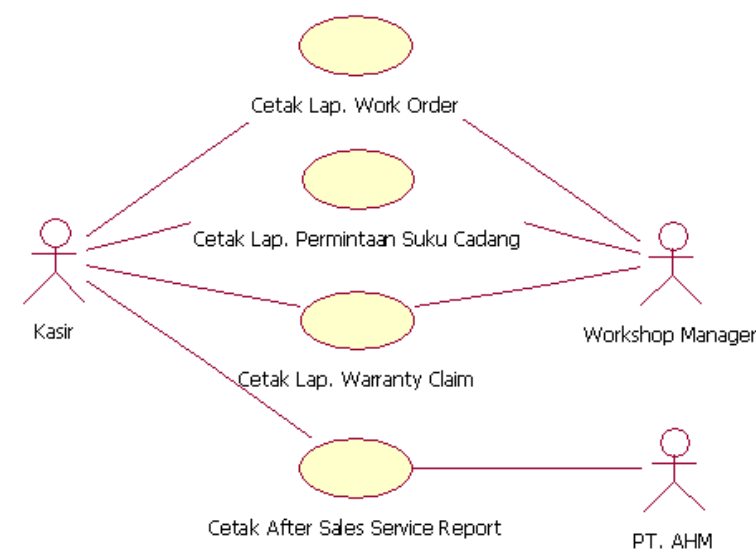

Gambar 5. Use Case Diagram Laporan

4. Activity Diagram

a. Pendataan Pelanggan

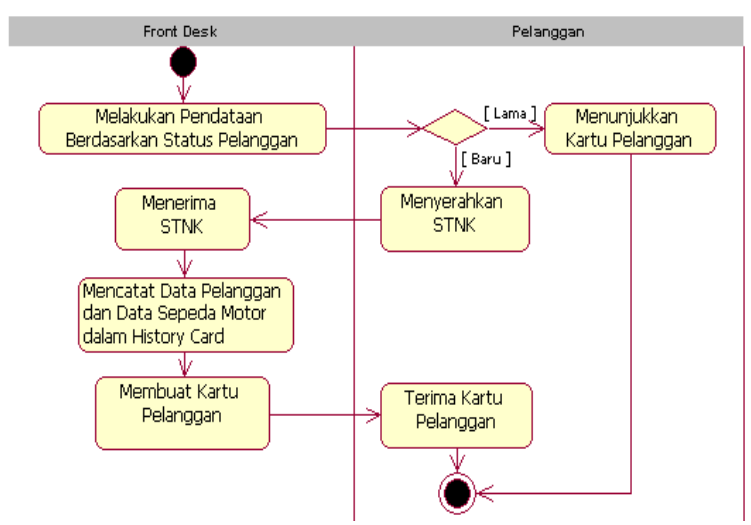

Gambar 6. Activity Diagram Pendataan Pelanggan

b. Penerimaan Order

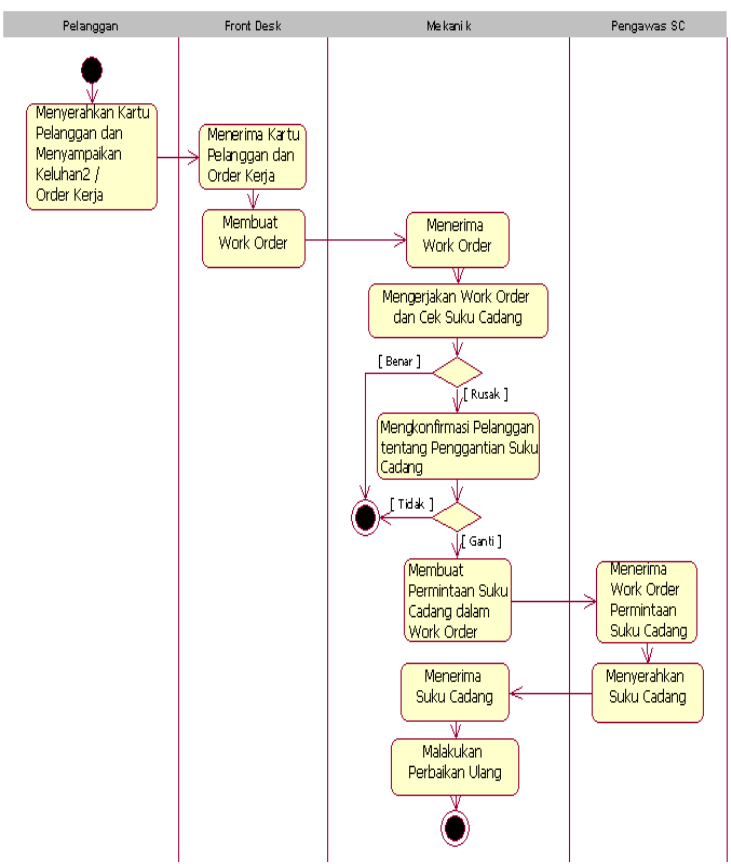

Gambar 7. Activity Diagram Penerimaan Order 
c. Pembayaran

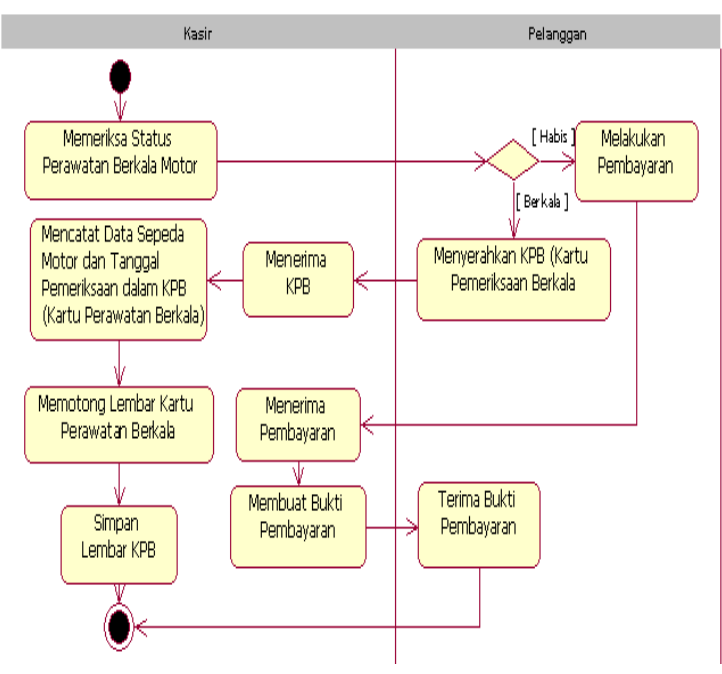

Gambar 8. Activity Diagram Pembayaran

d. Pengajuan Claim

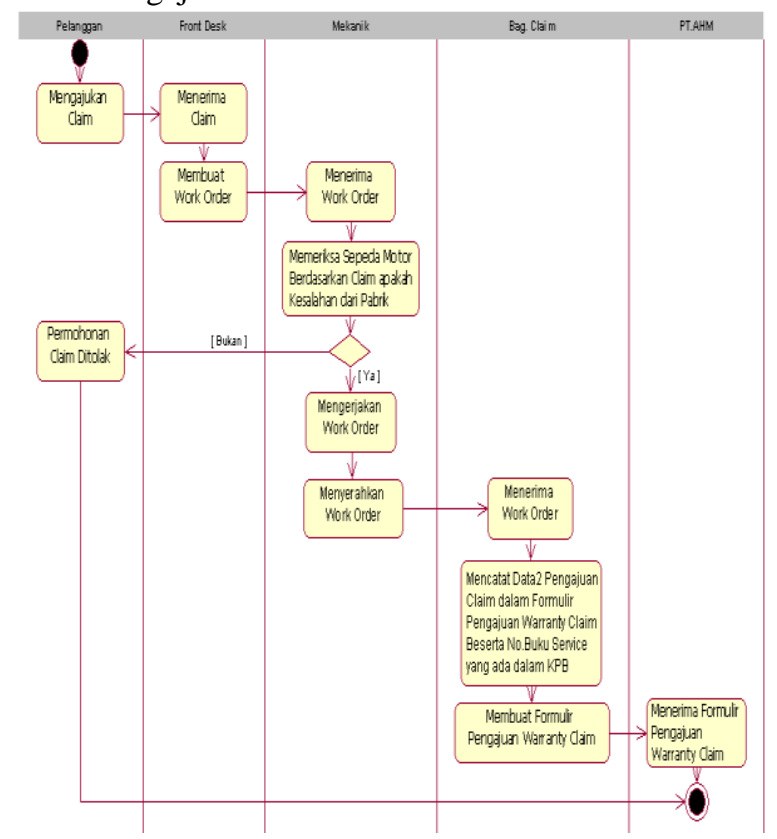

Gambar 9. Activity Diagram Pengajuan Claim

e. Buat Laporan

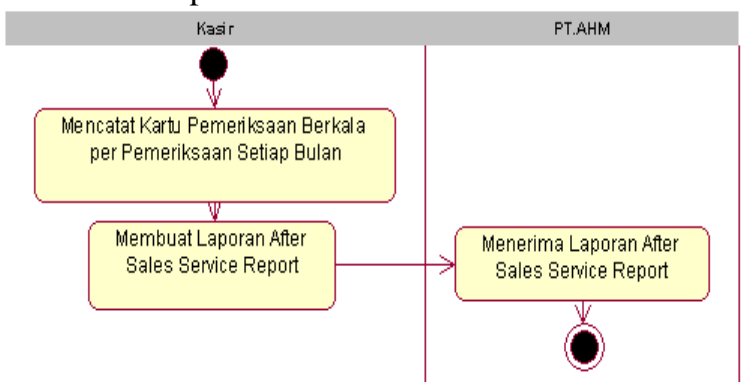

Gambar 10. Activity Diagram After Sales Service Report
B. Tahap Desain Sistem (Design System)

1. Logical Database Design

Memilih DBMS yang akan digunakan untuk mengimplementasikan desain database dan mengubah konsep desain database menjadi sebuah skema database dalam model data dari DBMS terpilih.

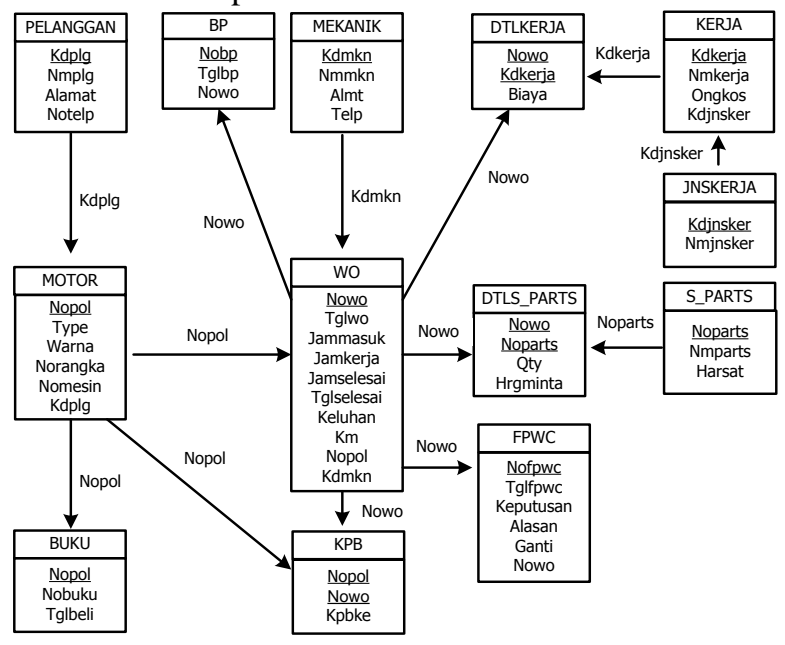

Gambar 11. Logical Record Structure ( LRS )

2. Desain Interface

a. Struktur Tampilan Menu

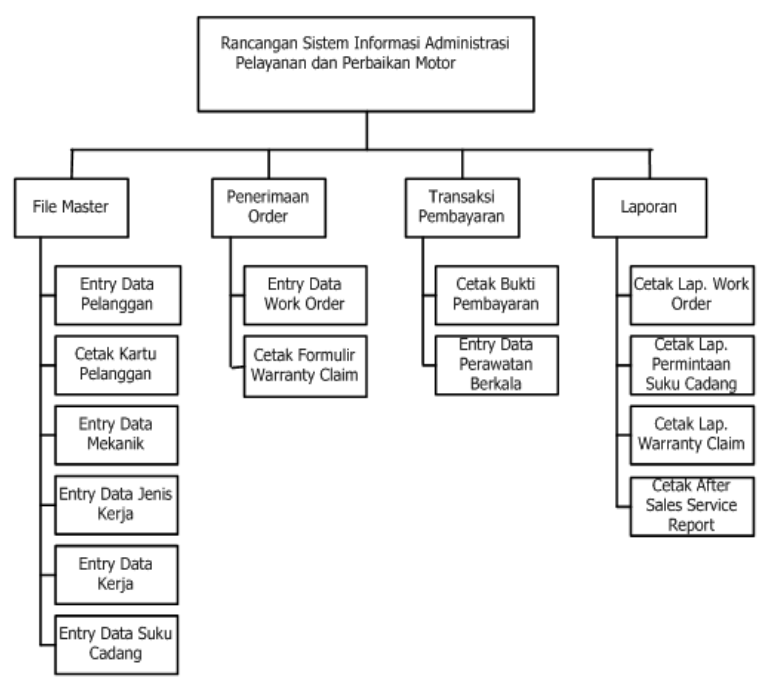

Gambar 12. Struktur Tampilan Menu 
b. Tampilan Cetak Kartu Pelanggan

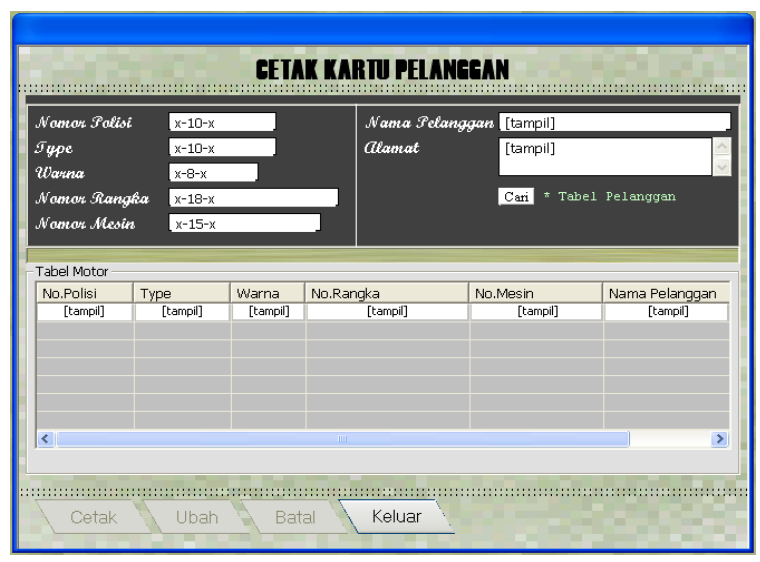

Gambar 13. Cetak Kartu Pelanggan

c. Tampilan Entry Data Work Order

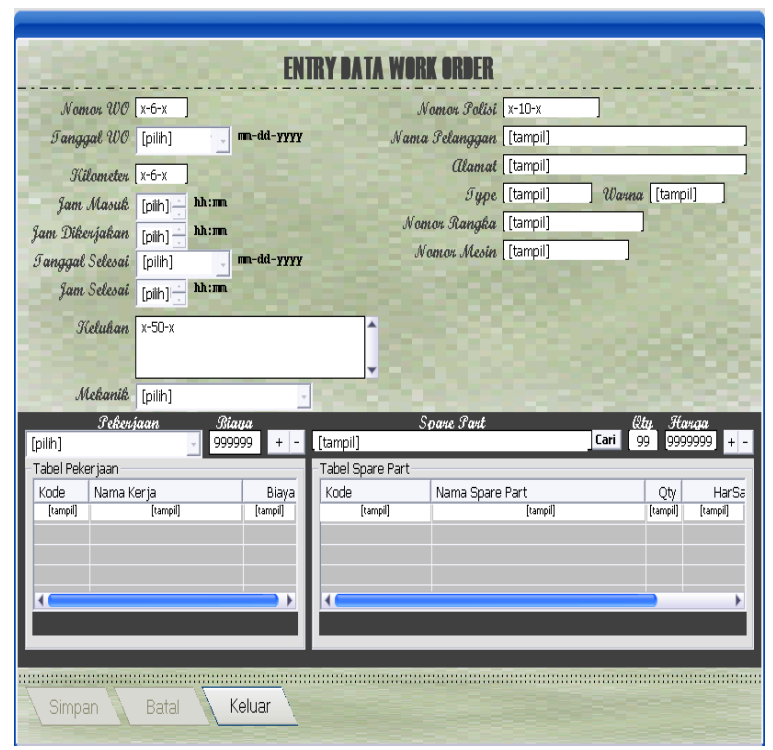

Gambar 14. Entry Data Work Order

d. Tampilan Cetak After Sales Service Report

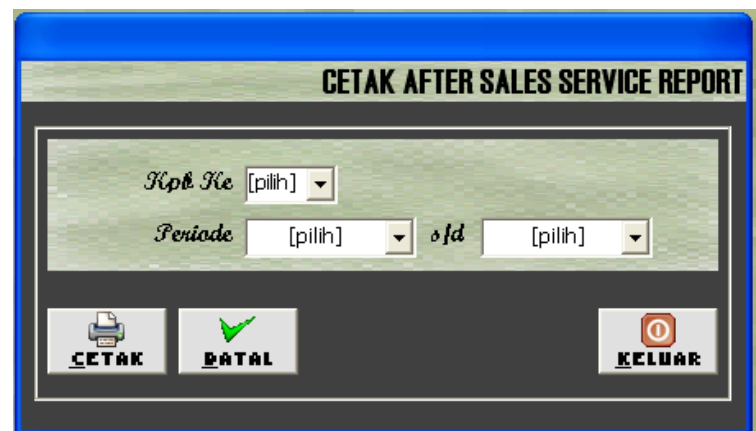

Gambar 15. Cetak After Sales Service Report

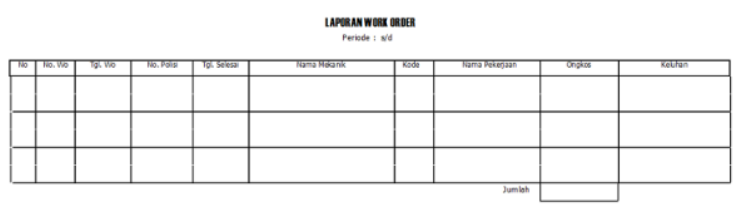

Gambar 16. Tampilan Laporan Work Order

f. Tampilan Laporan Permintaan Suku Cadang

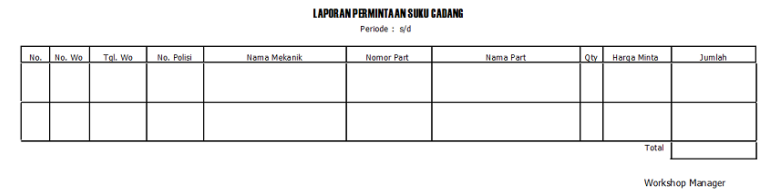

Gambar 17. Tampilan Laporan Permintaan Suku Cadang

g. Tampilan Laporan Pengajuan Warranty Claim

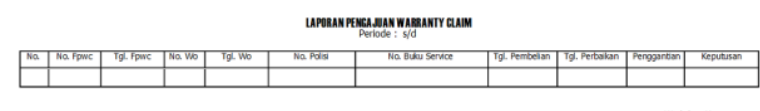

Gambar 18. Tampilan Laporan Pengajuan Warranty Claim

h. Tampilan After Sales Service Report

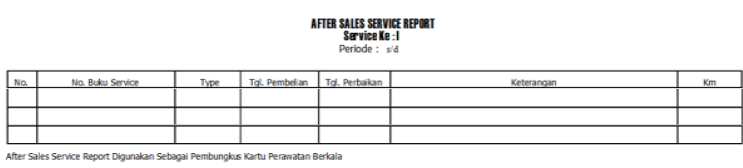

Gambar 19. Tampilan After Sales Service Report

C. Tahap Implementasi (Implementation)

Dalam pengimplementasian sistem diperlukan beberapa tahapan perencanaan:

a. Persiapan awal (data dan software)

b. Instalasi software

c. Penentuan operator

d. Pelatihan pengguna

e. Sosialisasi kepada pihak-pihak yang terlibat dalam sistem

f. Uji coba sistem

g. Evaluasi dan perbaikan sistem

h. Dokementasi

Pengujian sistem dengan Black-Box Testing

e. Tampilan Laporan Work Order 
Tabel 2. Pengujian Black-Box Testing

\begin{tabular}{|c|c|c|c|}
\hline No. & $\begin{array}{c}\text { Nama } \\
\text { Pengujian }\end{array}$ & Hasil yang diharapkan & $\begin{array}{l}\text { Kesimp } \\
\text { ulan }\end{array}$ \\
\hline & $\begin{array}{l}\text { Entry Data } \\
\text { Pelanggan }\end{array}$ & $\begin{array}{l}\text { Front desk dapat menginput } \\
\text { data pelanggan berdasarkan } \\
\text { STNK dan informasi dari } \\
\text { pelanggan dalam master } \\
\text { pelanggan }\end{array}$ & Valid \\
\hline 2. & $\begin{array}{l}\text { Cetak Kartu } \\
\text { Pelanggan }\end{array}$ & $\begin{array}{l}\text { Front desk dapat menginput } \\
\text { data sepeda motor } \\
\text { berdasarkan STNK yang } \\
\text { diserahkan pelanggan } \\
\text { dalam master motor } \\
\text { Front desk dapat mencetak } \\
\text { kartu pelanggan }\end{array}$ & Valid \\
\hline 3. & $\begin{array}{l}\text { Entry Data } \\
\text { Mekanik }\end{array}$ & $\begin{array}{l}\text { Front desk dapat menginput } \\
\text { data mekanik berdasarkan } \\
\text { data mekanik dari technical } \\
\text { inspector dalam master } \\
\text { makanik }\end{array}$ & Valid \\
\hline & $\begin{array}{l}\text { Entry Data } \\
\text { Jenis Kerja }\end{array}$ & $\begin{array}{l}\text { Front desk dapat menginput } \\
\text { data jenis pekerjaan } \\
\text { berdasarkan data jenis kerja } \\
\text { dari technical inspector } \\
\text { dalam master jenis kerja }\end{array}$ & Valid \\
\hline & $\begin{array}{ll}\text { Entry } & \text { Data } \\
\text { Kerja } & \end{array}$ & $\begin{array}{l}\text { Front desk dapat menginput } \\
\text { data pekerjaan berdasarkan } \\
\text { data kerja dari technical } \\
\text { inspector dalam master } \\
\text { kerja }\end{array}$ & Valid \\
\hline & $\begin{array}{l}\text { Entry Data } \\
\text { Suku } \\
\text { Cadang }\end{array}$ & 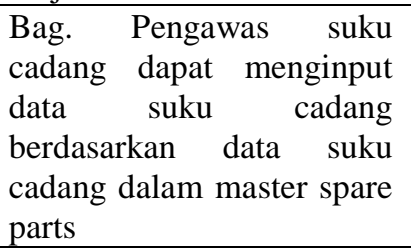 & Valid \\
\hline 7. & \begin{tabular}{|ll} 
Entry & Data \\
Work & Order
\end{tabular} & $\begin{array}{ll}\text { Front desk dapat menginput } \\
\text { data work order } \\
\text { berdasarkan work order } \\
\text { dari technical inspector }\end{array}$ & Valid \\
\hline & \begin{tabular}{|l} 
Cetak \\
Formulir \\
Warranty \\
Claim
\end{tabular} & $\begin{array}{l}\text { Bagian claim dapat } \\
\text { menginput data claim } \\
\text { berdasarkan work order } \\
\text { dan kartu perawatan } \\
\text { berkala } \\
\text { Bagian claim dapat } \\
\text { mencetak formulir } \\
\text { pengajuan warranty claim }\end{array}$ & Valid \\
\hline 9. & $\begin{array}{l}\text { Cetak Bukti } \\
\text { Pembayaran }\end{array}$ & $\begin{array}{l}\text { Kasir dapat menginput data } \\
\text { pembayaran berdasarkan } \\
\text { work order/ order kerja } \\
\text { Kasir dapat mencetak bukti } \\
\text { pembayaran }\end{array}$ & Valid \\
\hline
\end{tabular}

\begin{tabular}{|l|l|l|l|}
\hline No. & $\begin{array}{c}\text { Nama } \\
\text { Pengujian }\end{array}$ & \multicolumn{1}{|c|}{ Hasil yang diharapkan } & $\begin{array}{c}\text { Kesimp } \\
\text { ulan }\end{array}$ \\
\hline 10. & $\begin{array}{l}\text { Entry Data } \\
\text { Perawatan } \\
\text { Berkala }\end{array}$ & $\begin{array}{l}\text { Kasir dapat menginput data } \\
\text { perawatan berkala } \\
\text { berdasarkan buku service } \\
\text { pelanggan }\end{array}$ & Valid \\
\hline 11. & Cetak Lap. & $\begin{array}{l}\text { Kasir dapat mencetak } \\
\text { Work Order } \\
\text { laporan work order setiap } \\
\text { akhir bulan berdasarkan } \\
\text { work order }\end{array}$ & Valid \\
\hline 12. & $\begin{array}{ll}\text { Cetak Lap. } \\
\text { Permintaan } \\
\text { Suku } \\
\text { Cadang }\end{array}$ & $\begin{array}{l}\text { Kasir dapat mencetak } \\
\text { laporan permintaan suku } \\
\text { cadang setiap akhir bulan } \\
\text { berdasarkan work order }\end{array}$ & Valid \\
\hline 13. & $\begin{array}{l}\text { Cetak Lap. } \\
\text { Warranty } \\
\text { Claim }\end{array}$ & $\begin{array}{l}\text { Kasir dapat mencetak } \\
\text { laporan warranty claim } \\
\text { setiap akhir bulan } \\
\text { berdasarkan work order } \\
\text { dan formulir penggajuan } \\
\text { warranty claim }\end{array}$ & Valid \\
\hline $\begin{array}{l}\text { 14. } \\
\text { Cetak After } \\
\text { Sales } \\
\text { Service } \\
\text { Report }\end{array}$ & $\begin{array}{l}\text { Kasir dapat mencetak after } \\
\text { sales service report setiap } \\
\text { akhir bulan yang } \\
\text { diserahkan }\end{array}$ & Valid \\
\hline
\end{tabular}

\section{IV.KESIMPULAN}

Berdasarkan penelitian ini, maka dapat diambil kesimpulan sebagai berikut :

1. Untuk dapat mengembangkan sistem informasi yang baik, diperlukan tahapan dalam pengembangannya. Sehingga dalam proses pembuatannya terencana dan terukur serta hasilnya sesuai konsep dan tujuan . Dimana dalam penelitian ini tahapan yang dilakukan adalah merencanakan kebutuhan sistem (Requirement Planning), desain sistem (Design System) dan melakukan implementasi (Implementation).

2. Berdasarkan hasil pengujian Black-Box Testing, sistem yang dikembangkan sudah sesuai dengan fungsinya sehingga tugas dan pekerjaan dari pengguna sistem lebih mudah dan cepat selesai, serta penyajian informasi dan laporan yang akan diberikan lebih cepat dan akurat.

3. Terdapat empat laporan yang akan dibuat sebagai pertanggung jawaban kasir ke workshop manajer, diantaranya laporan work order, laporan permintaan suku cadang, laporan warranty claim dan after sales service report. 


\section{DAFTAR PUSTAKA}

[1] Aswati, S., Sabir Ramadhan, M., Udi Firmansyah, A., \& Anwar, K. (n.d.). STUDI ANALISIS MODEL RAPID APPLICATION DEVELOPMENT

DALAM PENGEMBANGAN SISTEM INFORMASI. MATRIK, vol.16, no.2, pp. 20-27, 2017.

[2] Daud, R., \& Windana, V. M. (n.d.). PENGEMBANGAN SISTEM INFORMASI AKUNTANSI PENJUALAN DAN PENERIMAAN KAS BERBASIS KOMPUTER PADA PERUSAHAAN KECIL (STUDI KASUS PADA PT. TRUST TECHNOLOGY). Manajemen dan Bisnis Sriwijaya, vol.12, no.1, pp. 17-28, 2014.

[3] Hanifah, S. I. (n.d.). AKUNTABILITAS DAN TRANSPARANSI

PERTANGGUNGJAWABAN ANGGARAN PENDAPATAN BELANJA DESA (APBDes). Jurnal Ilmu \& Riset Akuntansi , Vol. 4, No. 8,pp. 1-15, 2015.

[4] Nofiyani. PENGEMBANGAN SISTEM PENUNJANG KEPUTUSAN BERBASIS WEB UNTUK MENENTUKAN BEST CUSTOMERS DENGAN MODEL RFM (RECENCY, FREQUENCY DAN MONETARY), METODE COMPARATIVE PERFORMANCE INDEX DAN ALGORITMA SINGLE LINKAGE STUDI KASUS CV. XYZ. Telematika Mkom , 7(2) : 144-153. 2015.

[5] Putra, D. S., \& Fauzijah, A. (n.d.). Perancangan Aplikasi Presensi Dosen Realtime Dengan Metode Rapid Application Development (RAD) Menggunakan Fingerprint Berbasis Web. Jurnal Informatika: Jurnal Pengembangan IT (JPIT), Vol.03, No.02, pp. 167-171, 2018.

[6] Sagala, J. R. (n.d.). MODEL RAPID APPLICATION DEVELOPMENT (RAD) DALAM PENGEMBANGAN SISTEM INFORMASI PENJADWALAN BELAJAR MENGAJAR. Mantik Penusa, vol.2, no.1, pp. 87-90, 2018.

[7] Setiyono, J., \& Sutrimah. (n.d.). ANALISIS TEKS DAN KONTEKS PADA IKLAN OPERATOR. PEDAGOGIA , vol.5, no.2, pp.297-310, 2016.

[8] Wahyuningrum, T., \& Januarita, D. Perancangan WEB e-Commerce dengan Metode Rapid Application Development (RAD) untuk Produk Unggulan Desa. SEMINAR NASIONAL TEKNOLOGI INFORMASI \& KOMUNIKASI TERAPAN. Semarang, 2014. pp. 81-88.

[9] Yuliana, W. (n.d.). PERAN SISTEM INFORMASI MANAJEMEN DALAM MENINGKATKAN KUALITAS
PELAYANAN PUBLIK DI KANTOR KECAMATAN SUNGAI KUNJANG KOTA SAMARINDA. eJournal Administrasi Negara , Vol.5 , No.3, pp. 6225-6239, 2017. 